\title{
ARRANJOS PRODUTIVOS LOCAIS NA INDÚSTRIA AUTOMOBILÍSTICA: OS CASOS DA FIAT/BETIM E DA FORD/CAMAÇARI ${ }^{1}$
}

\author{
Maria Inês Cunha Miranda²
}

\section{Resumo:}

Ao longo do século XX, as pequenas e médias empresas passaram a sofrer com os impactos da crescente globalização, por não obterem as mesmas capacidades competitivas em relação aos grandes conglomerados. Para contornar deficiências competitivas, as empresas de pequeno e médio porte vêm crescentemente interagindo para que possam obter maiores chances de sobrevivência e aumento da inovação tecnológica, estabelecendo, portanto, vínculos com instituições de ensino (Universidades) e também eventualmente com empresas de grande porte. Neste sentido, o presente trabalho teve como objetivo a análise do nível de interação, suas respectivas formas de governança, de aprendizado e de inovação tecnológica das pequenas e médias empresas do setor automotivo com as empresas multinacionais Ford e Fiat no nordeste e sudeste brasileiro.

Palavras-chave: aglomeração, interação entre atores locais, desenvolvimento regional, aprendizado.

\begin{abstract}
:
During the XX century, the small and average size companies went through struggling times caused by the impact of the globalization increase. They did not have the same competitives capacities if compared with the big conglomerates. To contour the competitive deficits, the small and average size companies are increasing to interact to be able to have more chances of surviving and increase the technology innovation. This will establish ties with the Teaching Institutions (Universities) and eventually with the big corporations. Following this thought, this actual presentation has as target the level of the interaction analysis, the respectives kind of leadership, knowledge and the technology innovation of the small and average size companies that belong to the automobile field like multinationals companies as Ford and Fiat located on north-east and south-east in Brazil.
\end{abstract}

Key-word: cluster, interaction between local actors, regional development, training.

\footnotetext{
${ }^{1}$ Artigo escrito sobre a orientação da Professora Dr. ${ }^{a}$ Marisa dos Reis A. Botelho para o Programa de Educação Tutorial (PET).

${ }^{2}$ Graduanda do curso de Ciências Econômicas do Instituto de Economia da Universidade Federal de Uberlândia. Email: mcunhamiranda@yahoo.com.br.
} 


\section{Introdução}

A internacionalização da indústria brasileira vem se intensificando desde o início dos anos 80 , sendo que na década subseqüente obteve-se a consolidação deste cenário. Com isto a competitividade das pequenas e médias empresas apresentou-se debilitada, pois antes da abertura comercial elas não possuíam a estruturação produtiva necessária para que competissem com as entrantes, levando isso em consideração, as mesmas não conseguiram acompanhar as inovações e acabaram por perder espaço para as firmas que entraram na cadeia produtiva do país naquele período.

Além deste fator apresentado anteriormente, de acordo com Santos, Crocco e Lemos (2002) o processo de abertura foi aliado a “(...) mudanças ocorridas a partir da década de 1970 no ambiente competitivo das empresas. Tais mudanças ocorreram simultaneamente à emergência de um novo paradigma tecnológico (baseado na microeletrônica), o qual tem imposto um processo produtivo mais intensivo em conhecimento" (p.150). Essa "reestruturação industrial”, termo utilizado por Resende \& Gomes (2006), “(...) foi marcada pela intensificação tecnológica de produtos e processos produtivos [...]. Essas inovações resultaram no aumento de flexibilidade dos processos produtivos, que passaram a atender rapidamente às modificações cada vez mais freqüentes da demanda" (p.69). Entretanto, essas transformações dificultaram o acesso às novas tecnologias pelas empresas de pequeno e médio porte, as quais não estavam capacitadas para a aquisição das mesmas.

Por esses motivos, nos períodos em que se efetuaram essas mudanças, se percebe dois significativos movimentos: um de descentralização dos grandes pólos industriais, devido a políticas governamentais como, por exemplo, extinção de certos tributos durante determinado período, vantagem essa concedida em meio a "guerras fiscais" entre estados federais; outro, de aglomeração geográfica de empresas de um mesmo setor, a qual pode ser municipal ou regional, o que por intermédio dessa proximidade espacial “(...) gera vantagens econômicas independentes da ação da empresa, que internalizadas levam a reduções do custo e melhoria dos produtos" (FERREIRA \& LEMOS, 2004, p. 47), denominadas genericamente como Arranjos Produtivos Locais (APL). Estas aglomerações produtivas tiveram origem no início do processo de industrialização brasileiro, por volta do começo do século XX, no entanto, 
tornaram-se mais estudadas a partir dos anos 90 por meio da metodologia de análise desenvolvida principalmente pela RedeSist ${ }^{3}$.

Nas ultimas décadas, a literatura tem destacado as externalidades positivas da proximidade territorial, em termos de difusão das tecnologias e do aprendizado, de um conjunto de unidades produtivas de um mesmo setor ou cadeia produtiva. Tendo em vista a relevância desse tema, cabe investigar de que forma essas externalidades são utilizadas nas aglomerações de redes de provedores, especialmente naquelas em que se encontram duas grandes empresas multinacionais da indústria automotiva, a Fiat e a Ford.

Nessa perspectiva, o presente trabalho está divido em três seções além desta introdução. Na primeira seção, apresenta-se uma breve introdução no âmbito teórico no que se refere a arranjos e sistemas produtivos locais. A segunda seção dedica-se ao estudo comparado dos dois arranjos com suas principais semelhanças e diferenças. Na terceira seção apresentam-se as considerações finais.

\section{1-Arranjos e Sistemas Produtivos Locais}

A formação das aglomerações está relacionada a trajetórias históricas de construção de identidades e de vínculos territoriais com uma base comum, seja cultural, social, política e/ou econômica, bases nas quais a vivência de todos os atores envolvidos gira em torno do processo produtivo.

Os primeiros estudos desenvolvidos nesta temática foram de A. Marshall, os quais estiveram pautados no desenvolvimento induzido a partir do dinamismo tecnológico de algumas aglomerações, principalmente as inglesas, por ele denominadas distritos industriais. Estes distritos industriais, baseados na experiência recente da Terceira Itália, são caracterizados, segundo Santos, Crocco e Lemos (2002) e também por Crocco et alli

\footnotetext{
(...) pela proximidade geográfica, especialização setorial, predominância de PMEs [pequenas e médias empresas], cooperação interfirmas, competição interfirmas determinadas pela inovação, troca de informações baseada na confiança socialmente construída, organizações de apoio ativas na oferta de serviços e parcerias estreitas com o setor público (2006,p. 152).
}

Nestes moldes são exemplos de distritos industriais modernos os da Terceira Itália, do Vale do Silício, na Califórnia e da região de Baden-Wurttemberg na Alemanha, entre outros

\footnotetext{
3 Rede de pesquisa sediada no Instituto de Economia da Universidade Federal do Rio de Janeiro (UFRJ), formada no ano de 1997 que visa os estudos na área de Arranjos e Sistemas Produtivos Locais, mantendo parcerias com vários centros de pesquisa brasileiros e estrangeiros. A RedeSist disponibiliza cerca de 30 estudos de caso, nos diversos estados brasileiros, os quais estão à disposição em sua própria página http://www.redesist.ie.ufrj.br/.
} 
(VARGAS, 2004, p. 7). A partir de estudos dos distritos acima mencionados foi desenvolvido o conceito de "eficiência coletiva", o qual conforme Naretto, Botelho e Mendonça

(...) destaca não só as externalidades positivas passivas e espontâneas decorrentes da aglomeração- tais como rápida difusão de informações sobre a produção local e acesso a equipamentos e matérias-primas-, mas sobretudo as possibilidades de ação conjunta entre empresas e entre estas e instituições públicas e privadas, que permitiriam às PMEs potencializar ganhos competitivos e à estrutura produtiva, no seu conjunto, melhorar sua inserção competitiva (2004, p. 62).

Quando se trata de sistemas produtivos e inovativos locais considera-se aquelas aglomerações em que a “(...) interdependência, articulação e vínculos consistentes resultam em interação, cooperação e aprendizagem, com potencial de gerar o incremento da capacidade inovativa endógena, da competitividade e do desenvolvimento local" (CASSIOLATO \& LASTRES, 2003, p.27). Neste tipo de aglomeração, o aprendizado é considerado a principal fonte de dinamismo tecnológico das empresas, pois baseia-se na acumulação de competências das mesmas. Desta forma, é tão relevante a compreensão das relações que os atores envolvidos estabelecem como a “(...) noção [...] econômica de reduções de custos via usufruto de economias de escala e reduções das porosidades do processo produtivo" (CROCCO et alli (2001) apud SANTOS, CROCCO \& LEMOS, 2002, p.152). Por isso, Crocco et alli salientaram que

\footnotetext{
a "economia baseada no conhecimento" é caracterizada por um ambiente competitivo intensivo em conhecimento, globalização produtiva e financeiramente, e liberalizada comercialmente. Entretanto, o conhecimento e os processos de aprendizagem e de construção de competências a ele relacionadas, na medida em que são processos essencialmente interativos e incorporados em pessoas, organizações e relacionamentos, são influenciados pelo território. (2006, p.212)
}

Tendo isso em vista, se faz necessário um ambiente propício para que os atores possam manter relações de proximidade, elevando o grau de interdependência entre eles. Conforme já destacado por Santos, Crocco e Lemes “(...) estas interdependências, por sua vez, requerem a proximidade cognitiva e física para que possam ser realizadas plenamente e dêem origem a processos de aprendizado coletivo e de difusão do conhecimento tácito e codificado entre as empresas" (2002, p.153). Além desses fatores apresentados, existem outras características inerentes às aglomerações espaciais, as quais podem ser observadas no quadro 1 .

\section{Quadro 1: Características comuns a aglomerações produtivas}




\begin{tabular}{|c|l|}
\hline Localização & Proximidade ou concentração geográfica. \\
\hline Atores & Grupo de pequenas empresas. \\
& Pequenas empresas nucleadas por grande empresa. \\
& Associações, instituições de suporte, serviços, ensino e \\
& pesquisa, fomento, financeiras. \\
\hline Características & Intensa divisão do trabalho entre as firmas. \\
& Flexibilidade de produção e organização. \\
& Especialização. \\
& Mão-de-obra qualificada. \\
& Competição entre firmas baseada em inovação. \\
& Estreita colaboração entre as firmas e demais agentes. \\
& Fluxo intenso de informações. \\
& Identidade cultural entre os agentes. \\
& Relação de confiança entre os agentes. \\
& Complementaridades e sinergias. \\
\hline
\end{tabular}

Fonte: Lemos, C. (1997). In: Cassiolato \& Szapiro (2003)

Em contraposição a estes sistemas inovativos apresenta-se o conceito de arranjos produtivos locais, os quais são caracterizados por aglomerações territoriais de agentes econômicos, políticos e sociais que têm enfoque voltado para atividades econômicas, além da formação e capacitação de recursos humanos, pesquisa, desenvolvimento e engenharia, definição essa desenvolvida pela RedeSist (CASSIOLATO \& LASTRES, 2003, p.27). Este conceito deve ser levado em consideração, porque em oposição a sistemas inovativos e distritos industriais, APLs não apresentam as seguintes características: níveis altos de confiança entre os atores locais, identidade cultural entre eles e a competição inter-firmas baseadas na inovação. Tendo isso em vista, não necessariamente APLs em função da proximidade geográfica, possuem dinamismo competitivo e inovativo, como destacado por Vargas (2004).

Aglomerações cujas características mais se assemelham a de APLs encontram-se mais presentes em países em desenvolvimento onde, em geral, não se verificam vínculos mais consistentes entre os agente e cooperação empresarial. No entanto, cabe salientar que, no caso brasileiro, existe um elevado número de arranjos muito diversificados no que se refere à idade, participação de empresas de grande porte, criação através da indução estatal ou incentivo privado, nível de desenvolvimento, dentre outras. Por esse motivo, apesar da crescente sistematização teórica do assunto, é difícil a comparação entre os diversos APLs, tendo em vista suas especificidades.

Como visto anteriormente, a proximidade territorial proporciona às empresas externalidades positivas (spillover effects), as quais incluem a formação e, às vezes com o apoio estatal, a qualificação da mão de obra; a atração de empresas do mesmo setor ou cadeia produtiva; serviços de apoio; fornecedores de equipamentos, sendo que estes podem ser 
novos, usados ou até mesmo produzidos em conjunto (empresa-fornecedor), de acordo com a especificidade do processo produtivo; fornecedores de matérias-primas; difusão do conhecimento e troca de informações (NARETTO, BOTELHO \& MENDONÇA, 2004, p. 72).

Como Vargas (2004) comenta, “(...) a proximidade territorial tende a conduzir o comportamento de uma região em relação à "como fazer as coisas" significando que o desenvolvimento regional tende a convergir para uma trajetória path dependent" (p.5). Isto implica que devido a essa interdependência, é propiciado aos atores sociais um "conhecimento coletivo", ou seja, ao interagirem os agentes aprimoram a sua rede de aprendizado, com isso adquirem a habilidade de gerarem conhecimento e, conseqüentemente, inovações para os seus processos produtivos. Nesta perspectiva, Diniz relata que

\begin{abstract}
a aglomeração, ao reduzir distâncias, facilitar a acessibilidade, permitindo o contato direto, face a face, e a presença de externalidades em termos de instituições de pesquisa, relações inter-firmas, trabalho qualificado facilita o fluxo de conhecimentos, facilitando o aprendizado e a inovação $(2001$, p.9)
\end{abstract}

Estes elementos estão imersos num contexto institucional, onde podem estar presentes instituições de ensino (universidades, escolas técnicas), incubadoras de empresas ${ }^{4}$, agências estatais e para-estatais de apoio, como Sebrae, Serviço Nacional da Indústria (Senai); centros de pesquisa, os quais decorrentes de interações formais ou informais, são relevantes para o desenvolvimento das inovações e também da infra-estrutura dos APLs. Levando em consideração que a maioria das empresas aglomeradas é de micro, pequeno e médio porte, verifica-se que a porcentagem do capital destinado ao investimento em atividades de Pesquisa e Desenvolvimento (P\&D) de tecnologias é, geralmente, menor do que de grandes empresas, por esse motivo é de extrema relevância a presença das instituições acima citadas, pelos benefícios que as mesmas podem oferecer aos APLs.

Considerando-se, conforme descrevem diversos autores ${ }^{5}$, que a atividade de inovação está relacionada aos mecanismos de obtenção de conhecimento, torna-se relevante compreender quais os principais canais de aprendizado dos agentes, devido ao fato que o mesmo ocorre de acordo com a forma que os atores locais interagem pesquisa e experiência prática. Com isto,

\footnotetext{
4 De acordo com Naretto, Botelho e Mendonça (2004), esse tipo de instituição é voltada para o apoio de empreendedores que pretendem criar uma micro ou pequena empresa, geralmente de base tecnológica, mas que não possuem recursos ou condições competitivas favoráveis para o estabelecimento da mesma (p. 69).

${ }^{5}$ Ver entre outros, os trabalhos desenvolvidos por Diniz (2001), no qual o autor se refere a quatro tipos de aprendizado: processo de aprender fazendo (learning by doing), aprender usando (learning by using), aprender interagindo (learning by interacting) e aprender aprendendo (learning by learning) (p. 10).
} 
(...) o aprendizado passa a ser descrito como a forma pela qual as firmas constroem, suplementam e organizam conhecimentos e rotinas em torno de competências e culturas inerentes, ao mesmo tempo em que adaptam e desenvolvem sua eficiência organizacional através da melhoria destas competências (DODGSON (1996) apud VARGAS (2004), p. 6).

Por isso, o processo de aprendizagem é considerado social e interativo, sendo que as instituições e os demais atores sociais podem modificar e aprimorar o mesmo de acordo com as especificidades locais e a criação dos novos conhecimentos. Desta forma, as instituições tornam-se, por vezes, o principal elemento no processo de evolução local, por moldarem a percepção dos agentes envolvidos, propiciando um ambiente seletivo em termos de inovações, acumulando e difundindo o conhecimento adquirido pelas empresas aglomeradas (VARGAS, 2004, p.6). Todavia, o comportamento institucional pode ser facilitador ou não de tal difusão do conhecimento, sendo assim, fundamental para o perfeito desenvolvimento cognitivo e inovativo do APL.

A importância da interação entre os agentes e da presença de instituições, para uma análise da dinâmica competitiva dos APLs e sistemas produtivos e inovativos locais, torna necessária a compreensão de sua forma de governança, ou seja, a maneira pela qual os atores locais se relacionam “(...) que envolve atividades interdependentes associadas tanto à organização de fluxos de produção como ao processo de geração, disseminação e uso de conhecimentos" (VARGAS, 2004, p. 12). Como colocado por Vargas, a maneira adotada pelos indivíduos e instituições para a resolução de problemas comuns é relevante na medida em que é perceptível a “(...) influência dos atores locais e externos [públicos e privados] na coordenação dos sistemas de produção e na própria trajetória de desenvolvimento e capacitação produtiva e inovativa das empresas" (2004, p.13).

Desta forma, o estudo desenvolvido pela Rede de Pesquisa em Sistemas Produtivos e Inovativos locais-RedeSist identifica duas formas principais de governança ${ }^{6}$ : o tipo hierárquica e o tipo redes. A forma hierárquica refere-se àquela em que se torna evidente o comando de uma ou várias grandes empresas, cabendo a ela(s) o papel de empresa(s) âncora(s) $(h u b)$. Esta denominação é proveniente da maneira pela qual essa(s) empresa(s) coordena $(\mathrm{m})$ o processo de produção e o tecnológico, sendo que a relação mantida entre a mesma e seus fornecedores ou atores correlatos assemelha-se a aros (spoke) de uma roda (SANTOS, CROCCO \& LEMOS, 2002, p. 158; CASSIOLATO \& SZAPIRO, 2003, p.43) e a tomada de decisão é completamente centralizada pela "empresa-líder". Por esse motivo, as

\footnotetext{
6 Para um maior aprofundamento do tema ver Santos, Crocco \& Lemos (2002); Suzigan, Garcia \& Furtado (2002) e Crocco et alli (2006).
} 
aglomerações com este tipo de governança são identificadas, por alguns autores, como huband-spoke ou "centro-radial". Neste caso, as relações de poder são ditadas pela empresa âncora, a qual cria “(...) um círculo virtuoso de cooperação, estimulando o desenvolvimento de capacitações e estabelecendo uma competitividade sistêmica" (CASSIOLATO \& SZAPIRO, 2003, p.43). No entanto, convém observar que neste tipo de aglomeração “(...) as empresas menores acabam por reter o maior impacto dos ajustes de produção e das crises vividas pelas empresas maiores, sendo alta sua taxa de mortalidade e informalidade" (BOTELHO \& GARCIA (2001) apud NARETTO, BOTELHO \& MENDONÇA (2004), p. $68)$.

A forma de governança do tipo redes baseia-se na aglomeração de MPMEs (micro, pequena e médias empresas), sem que haja qualquer nível de hierarquia entre elas. O número de aglomeradas é bastante significativo, sendo assim, o poder de tomada de decisão é descentralizado, por isso, nenhuma empresa é dominante, em contraposição ao caso anterior. As redes permitem a cooperação e a confiança entre os agentes aprimorando um "espaço de aprendizagem coletivo”, no qual “(...) as idéias são trocadas e desenvolvidas e o conhecimento compartilhado numa tentativa coletiva de melhorar a qualidade de produtos e processos, de ocupar segmentos de mercado mais lucrativos, de coordenar ações e de realizar a solução de problemas conjuntamente" (SANTOS, CROCCO \& MENDONÇA, 2004, p.153).

De acordo com a caracterização adotada por Botelho (2008) encontram-se três tipos principais de aglomeração no Brasil: aglomerações de setores tradicionais, aglomerações de base tecnológica e aglomerações formadas por rede de provedores.

As aglomerações de setores tradicionais são as que possuem características mais próximas dos distritos industriais italianos? ${ }^{7}$. Eles se encontram em setores de calçados (aglomerações do Vale dos Sinos-RS e de Franca-SP), na indústria têxtil (Americana-SP, Vale do Itajaí-SC) e na indústria de móveis (São Bento do Sul-SC, Votuporanga-SP). Segundo Botelho (2008), este tipo de arranjo teve “(...) sua origem determinada por razões de mercado, em geral em função da oferta de matérias-primas ou qualificações profissionais, o que fez com que haja uma identificação muito forte de algumas regiões com o tipo de concentração setorial existente" (p.4). Sobre a forma de governança, as aglomerações de setores tradicionais apresentam-se em forma de redes, devido à semelhança com os distritos industriais italianos. Entretanto, as empresas dos setores tradicionais são pouco especializadas

\footnotetext{
7 Para efeito de comparação com os arranjos produtivos locais, Botelho (2008) utiliza como referência o modelo de distritos industriais, especialmente os italianos.
} 
e tendem a realizar grande parte ou o todo o processo produtivo, sendo assim, elas tornam-se concorrentes e “(...) quando têm parte de sua produção externalizada, esta ocorre em esquemas muitos precários de subcontratação, cuja intenção principal é a redução de custos a curto prazo (em geral do trabalho) e não a busca de especialização. Assim a divisão do trabalho entre as distintas unidades produtivas é pequena e não favorece a constituição de redes empresariais baseadas na cooperação"(BOTELHO, 2008, p.10).

As aglomerações de base tecnológica assemelham-se à tipificação de pólos tecnológicos, são menos numerosas e mais recentes no Brasil do que as de setores tradicionais. É o caso dos APLs de Campinas-SP (informática, eletrônica e telecomunicações), São Carlos-SP (novos materiais, ótica e mecânica), São José dos Campos(SP indústria aeronáutica), Blumenau-SC (software), Belo Horizonte-MG (biotecnologia), dentre outras. As aglomerações dos setores de base tecnológica nasceram do apoio estatal entre os anos de 1950 a 1970 e são geralmente vinculadas a Universidades, centros de pesquisa e a incubadoras. Apesar disto, as interações estabelecidas entre aquelas instituições e este tipo de aglomeração são bastante frágeis e, em certos termos, incompletas. Geralmente por apresentarem governança da forma hierárquica, as relações entre os atores envolvidos nesses setores de tecnologia de ponta tornam-se debilitadas, pois se baseiam em redes de subcontratação. Então, nota-se certa dificuldade destas aglomerações em manterem posição de destaque no mercado mundial. Nas palavras de Naretto, Botelho e Mendonça, “(...) verifica-se forte luta competitiva com os concorrentes externos e o resultado em geral é a venda para esses mesmos concorrentes" (2004, p.84). Além disso, essas aglomerações têm tido barreiras impostas aos seus produtos pela falta de adequação técnica às normas dos compradores, que incluem desde barreiras fitossanitárias até exigências de homologação de produto exigida para aviões (NARETTO, BOTELHO \& MENDONÇA, 2004, p.85).

As aglomerações do tipo rede de provedores são aquelas “(...) sustentadas por grandes empresas em setores de tecnologia complexa, que se comportam como um núcleo ao qual estão articuladas pequenas e médias empresas (PMEs), normalmente em esquemas formais de subcontratação. A base da competitividade das PMEs está em sua especialização e produtividade" (BOTELHO, 2008, p.5). Com isto percebe-se um alto nível de hierarquia, sendo assim, existem fortes assimetrias no que se refere a diferenças de tamanho e poder de mercado, por isso, a cooperação é bastante debilitada. São exemplos presentes em Betim-MG e Camaçari-BA da indústria automotiva, os quais serão para efeito de análise aprofundado neste trabalho. Em geral, estes tipos de aglomeração estão vinculados a fortes incentivos fiscais tanto estaduais como federais. Como as PMEs estão geralmente articuladas a grandes 
empresas oligopolísticas, “(...) a concorrência para a redução de custos e melhorias de qualidade fizeram também que aumentasse a participação de produtos e produtores estrangeiros. Assim, as oportunidades para as PMEs se reduziram[...]"(BOTELHO, 2008, p.8). Isto se deve em grande parte à total dependência estabelecida entre as PMEs e empresas de grande porte, no que tange às especificidades produtivas, pois estas são fixadas de acordo com a demanda dessas empresas oligopólicas. Sendo assim, PMEs possuem sua competitividade vinculada aos interesses de empresas multinacionais, no caso da indústria automobilística, tendo sua sobrevivência entrelaçada àquelas empresas.

Tendo em vista o explicitado anteriormente, exemplifica-se no quadro 2 algumas aglomerações presentes no ambiente brasileiro:

Quadro 2 - Padrões de Aglomerações

\begin{tabular}{|l|l|l|l|l|}
\hline Origem & Iniciativa & Setores Típicos & Formato & Porte \\
\hline $\begin{array}{l}\text { Base de recursos } \\
\text { naturais e oferta } \\
\text { de trabalho e } \\
\text { insumos }\end{array}$ & Espontâneo & $\begin{array}{l}\text { Indústria tradicional } \\
\text { Plásticos } \\
\text { Agropecuária } \\
\text { Turismo }\end{array}$ & $\begin{array}{l}\text { Aglomeração produtiva } \\
\text { Distrito industrial }\left(^{*}\right)\end{array}$ & MPME \\
\hline $\begin{array}{l}\text { Incentivos } \\
\text { fiscais }\end{array}$ & Estado direto & Indústria tradicional & Aglomeração Produtiva & PME \\
\hline $\begin{array}{l}\text { Investimento em } \\
\text { ensino e P\&D }\end{array}$ & Estado direto & $\begin{array}{l}\text { Informática } \\
\text { Aeroespacial } \\
\text { Eletrônica } \\
\text { Biotecnologia } \\
\text { Serviços }\end{array}$ & $\begin{array}{l}\text { Pólos tecnológicos } \\
\text { Incubadoras }\end{array}$ & MPE \\
\hline $\begin{array}{l}\text { Atração e } \\
\text { criação de } \\
\text { empresas líderes }\end{array}$ & $\begin{array}{l}\text { Estado } \\
\text { indireto }\end{array}$ & $\begin{array}{l}\text { Automóveis } \\
\text { Mecânica } \\
\text { Eletroeletrônica } \\
\text { Informática }\end{array}$ & $\begin{array}{l}\text { Subcontratação } \\
\text { Cadeias produtivas }\end{array}$ & PME \\
\hline
\end{tabular}

Fonte: Naretto, Botelho \& Mendonça (2004).

Deste modo, considerando o panorama acima apresentado a respeito dos arranjos e sistemas produtivos locais, percebe-se a relevância deste tipo de aglomeração produtiva para a sobrevivência das MPMEs no ambiente competitivo em que se encontram. $\mathrm{O}$ aparato institucional local em interação com as empresas pode proporcionar as condições necessárias para o aprendizado, visando a criação das inovações tecnológicas. Tendo isso em vista, as MPMEs adquirem vantagens competitivas, as quais impulsionam o crescimento das mesmas e, conseqüentemente, o desenvolvimento local, mesmo nos APLs em que são frágeis os mecanismos de cooperação entre os agentes.

Nesta perspectiva, faz-se necessário o estudo de casos empíricos, os quais se concentram em aglomerações já consolidadas, partindo para a avaliação das contribuições que 
as mesmas propiciam para o desenvolvimento local. Levando isso em consideração, o presente trabalho propõe-se a estudar dois APLs da cadeia automotiva, a Fiat (Betim-MG) e a Ford (Camaçari-BA), no que tange às especificidades dos atores locais e suas respectivas formas de interação.

\section{2- APLs de Minas Gerais e da Bahia}

\section{1- A Fiat em Minas Gerais}

A implantação do arranjo produtivo da Fiat Automóveis se deu em 1975, na cidade metropolitana de Belo Horizonte, no município de Betim. A decisão de tal instalação teve fundamento na forte atuação do Estado no que se refere a intensos incentivos físcais, financeiros e de infra-estrutura, além do mesmo ter-se tornado sócio minoritário da montadora no estado (LIMA et alli, 2002. p. 12). Segundo Lemos et alli, os incentivos fiscais recebidos pela subsidiária foram altos o suficiente para compensarem os dispêndios iniciais que a mesma teria com a instalação e operação, longe do grande centro de São Paulo e também de sua já capacitada rede de infra-estrutura educacional e urbana a qual proporcionava toda uma indústria de suporte completa (2000, p.9).

Além da concessão de incentivos fiscais, o governo estadual desempenhou um importante papel no que se refere à implantação de uma rede de fornecedores, ou seja, à constituição de uma indústria de autopeças no Estado, conhecido como a "mineirização" dos fornecedores da montadora, resultando na relocalização geográfica dos fornecedores à montadora, como verificado por Lemos e Diniz (1998). Aliado a esse processo de mineirização dos fornecedores, entre a década de 80 e 90, a Fiat implementou o "Projeto J", o qual consistia na

(...) mineirização, terceirização, sistemas de peças, nacionalização e racionalização do parque, tendo em vista a crescente concorrência nos mercados de produtos, que impõe às montadoras uma maior customização e flexibilidade da produção e entrega de bens e serviços (LIMA et alli, 2002, p.12).

No que tange à indústria de autopeças mineira constata-se que é “(...) composta por 150 empresas, onde a maior parte é classificada como pequena e média, quando o critério de tamanho é dado pelo número de empregados. No entanto, quando é utilizado o critério de valor de produção pode-se verificar que a maior participação é das empresas classificadas como líderes ou sistemistas" (LEMES et alli (2000) apud SANTOS, CROCCO \& LEMOS, 2002, p. 162). Com o Projeto J, “(...) a Fiat começou a promover um extensivo processo de desverticalização de sua produção através da terceirização de partes e componentes para 
fornecedores independentes de "sistemas integrados automotivos" ou sistemistas, capazes de atender as condições técnicas e de qualidade impostas pela Fiat. [...] A [montadora] relacionase com aproximadamente 50 fornecedores de sistemas integrados, os quais conseqüentemente subcontratam outras empresas para comporem a oferta de produtos especializados (LEMES et alli, 2000, p. 13), o que leva as sistemistas a coordenarem e organizarem os fornecedores das camadas subseqüentes. Com tais mudanças no relacionamento montadora/fornecedores permitidas pelo programa de "mineirização", houve por parte da Fiat “(...) uma aproximação física da maior parte de seus fornecedores [...], o que fica mais evidente ao se verificar que o número de fornecedores locais e o volume de compras passam, respectivamente, de 35 e $26 \%$ em 1989 para 90 e 75\% em 1998” (LEMES et alli, 2000, p.14). Então, devido à essa proximidade física dos fornecedores em torno da região metropolitana de Belo Horizonte, constitui-se uma verdadeira cadeia vertical de fornecedores.

Ademais, com a introdução do just in time na cadeia produtiva, aproximou-se os fornecedores da montadora sendo caracterizado pela “(...) crescente dependência entre as partes, como de uma estratégia através da qual a Fiat reduz sua base de fornecedores e simultaneamente estimula a responsabilidade mútua no que concerne a qualidade da produção com os fornecedores restantes" (LEMES et alli, 2000, p. 15). Tendo isso em vista, percebe-se que a Fiat possui governança do tipo hierárquica, na qual seus fornecedores se comportam como aros em torno da mesma, sendo o controle das decisões exclusivo da montadora. Contudo, segundo Santos, Crocco \& Lemes,

$$
\begin{aligned}
& \text { (...) o fato de a empresa não ser a sede mundial do grupo altera substancialmente a } \\
& \text { forma de governança industrial, com reflexos negativos sobre a capacidade } \\
& \text { tecnológica e produtiva dos fornecedores de segundo e terceiro níveis e sobre a } \\
& \text { absorção de mão-de-obra de diferentes qualificações (2002, p. 164). }
\end{aligned}
$$

Entretanto, ao longo da década de 90, esta indústria vem passando por um processo de desnacionalização, sendo muitos fornecedores locais absorvidos por fornecedores globais. Este processo tem sido denominado por alguns autores de "italianização" da indústria mineira de autopeças, em analogia à antiga "mineirização", devido ao fato da Fiat estimular a entrada de fornecedores globais que a mesma já possui relacionamento duradouro na Itália (SANTOS, CROCCO \& LEMES, 2002, p. 162). Com isso, observa-se que o processo de "italianização", tornou limitado o desenvolvimento tecnológico local, pois como salientado por Lemos \& Diniz

se de um lado o sistema organizacional just in time facilita o aprendizado através da interação grande usuário e fornecedor local, por outro lado, é um limitador do desenvolvimento de empresas locais inovadoras, tendo em vista o critério seletivo das empresas chamadas de "primeira linha", que em geral são subsidiárias de 
fornecedores internacionais ou joint ventures parceiras da matriz da empresa-mãe (1998, p.24).

Com essa concentração das atividades de P\&D nas matrizes da empresa em conjunto com seus fornecedores globais, mantêm o arranjo de Betim como mero pólo produtivo. Por esse motivo, Lemos et alli constata que

(...) o fato de que os principais laboratórios de P\&D estão baseados fora do país é, sem dúvida, decisivo para explicar a baixa interação entre os agentes no que diz respeito tanto ao desenvolvimento das capacidades tecnológicos quanto a "aliança" em outras capacidades. Além disto, a fraqueza dos mecanismos de transmissão intra e/ou inter indústria e vertical e/ou horizontal de tecnologia compromete a intensidade e o alcance dos efeitos de transbordamento (2000, p. 27).

Neste sentido, a principal estratégia da montadora consiste em “(...) reforçar o sistema local como uma plataforma de produção e recentrar o esforço tecnológico na matriz, que por sua própria natureza, demanda uma significativa indivisibilidade locacional" (SANTOS, CROCCO \& LEMES, 2002, p. 163). Tendo isso em vista, o arranjo da Fiat torna-se limitado ao âmbito produtivo, sendo que os esforços de cooperação entre montadora/sistemistas restritos a

(...) inovações organizacionais no processo de produção e distribuição, especialmente na implantação e no desenvolvimento do just in time (JIT), com efeitos positivos de indução no just in time interno nas firmas da rede vertical de fornecedores. De outro lado, a montadora, através de programas específicos, provém ajuda técnica, operacional e/ou gerencial para a identificação de ineficiências de seus fornecedores que levem à redução do preço final do produto fornecido (SANTOS, CROCCO \& LEMOS, 2002, p. 163)

\section{2- A Ford na Bahia}

A montadora Ford instalou-se na cidade Camaçari, na região metropolitana de Salvador, em 1999. A escolha da localidade se deu em função da proximidade do Porto de Aratu (aproximadamente $45 \mathrm{~km}$ ) e também devido a incentivos fiscais por parte do governo do estado com o fim de compensar os custos de instalação da empresa no local. De acordo com Silva et alli, o governo estadual

(...) forneceu um conjunto de incentivos fiscais, financeiros e de infra-estrutura para a instalação do complexo Ford, dos quais muitos estavam amparados no Programa Especial de Incentivo ao Setor Automotivo da Bahia- Proauto, com o objetivo de financiar capital de giro, investimentos fixos e despesas dos empreendimentos, de engenharia e P\&D (NAJBERG \& PUGA (2003) apud SILVA et alli, 2004, p. 4).

Como no caso da Fiat, a implantação da Ford verificou-se mediante as condições favoráveis proporcionadas pelo Regime Automotivo Brasileiro. Contudo, foi por meio de uma redefinição estratégica da montadora, o Projeto Amazon, que foi consolidada a implantação de tal complexo, pois este projeto contemplava o estabelecimento de novas plantas produtivas em países emergentes, tornando-se crucial a vinda da montadora para o Brasil. 
Da mesma forma que em Betim, na qual o governo estadual incentivou a "mineirização" dos fornecedores, em Camaçari o governo estadual tenta atingir esse patamar de "baianização" que corresponderia a $60 \%$ do total dos fornecedores com o intuito de incentivar o desenvolvimento local (LIMA et alli, 2002, p. 20). Neste local, a Ford conta com cerca de trinta e três empresas sistemistas, as quais segundo Guerra \& Mercês,

(...) são na sua grande maioria, controladas por empresas globais que suprem as grandes montadoras automobilísticas em diversos empreendimentos pelo mundo. $\mathrm{O}$ espaço físico por elas [as sistemistas] ocupado em Camaçari localiza-se na própria linha de produção e nele se confundem atividades administrativas rotineiras e de montagem (2004, p. 2).

Constata-se que esse arranjo produtivo é fortemente marcado pela presença de pequenas e micro empresas, que em quase sua totalidade são controladas por empresas globais, as quais já suprem as montadoras a nível mundial.

Deste modo, como verificado por Guerra e Mercês (2004), “(...) os sistemistas de Camaçari assemelham-se a uma quase firma, denominação empregada para subsidiárias de multinacionais ou estatais que se subordinam às matrizes ou a ministérios e não possuem independência decisória" (p. 2). Dessas trinta e três empresas, a montadora classifica 26 em fornecedores produtivos e 7 em não-produtivos, de acordo com a posição que o bem/serviço produzido ocupa no processo produtivo (GUERRA \& MERCÊS, 2004, p. 2). Com isto, podese verificar que a Ford, da mesma maneira que a Fiat, exerce uma governança do tipo hierárquica, devido à alta dependência que as sistemistas mantêm. Na perspectiva de Lima et alli,

(...) o resultado deste processo é um grau de eficiência mais elevado à medida que a montadora dedica-se às atividades de maior valor agregado, transferindo aquelas de menor valor agregado para os seus fornecedores, que operam integrados entre si e sob a coordenação e supervisão da montadora (2002, p.19).

\section{3- Estudo de Casos: a comparação entre os arranjos Fiat e Ford}

Como visto anteriormente, a Fiat teve a capacidade de instituir uma articulada rede de fornecedores só que, no entanto, não adquiriu a capacidade de desenvolver a cooperação entre os agentes participantes do arranjo, aspecto salientado por Lemos et alli (2000). Devido à intensa terceirização do processo produtivo, a estrutura dos fornecedores tornou-se uma rede de subcontratação bastante hierarquizada. Entretanto, esta rede de subcontratação é de fundamental importância para o desenvolvimento do just in time interno e externo, o que "(...) tem permitido a redução ao mínimo dos estoques no galpão da montadora, possibilitando a ampliação do espaço físico das linhas de montagem e aumento da produção/dia de veículos" (LEMOS \& DINIZ, 1998, p. 16). 
Com isso, a cooperação existente entre montadora e seus fornecedores fica limitada ao aprimoramento da forma organizacional, ou seja, ao aperfeiçoamento das técnicas do just in time. Por esse motivo, torna-se evidente que o

(...) aprendizado via cooperação na rede de fornecedores é limitado ao know-how de novos métodos organizacionais, gerenciais e produtivos, com transbordamentos para o processo de produção quando este experimenta a introdução de máquinas de automação industrial, que exigem novas formas de organização do processo de trabalho (SANTOS, CROCCO \& LEMOS, 2002, p. 164).

Tendo isso em vista, percebe-se também que o arranjo produtivo da Fiat possui estreita capacidade de inovação, restringindo-se a aspectos adaptativos do projeto desenvolvido na matriz. De acordo com Santos, Crocco \& Lemos, “(...) os aspectos fundamentais do esforço de inovação-concepção do desenho básico, desenvolvimento do projeto e teste do protótipo e mesmo aqueles mais intensivos em conhecimento, relacionados à adoção e adaptação, são realizados nos departamentos de P\&D da matriz" (2002, p. 162). Estas estruturas mantêm-se devido à estratégia da Fiat de reforçar o arranjo como plataforma estritamente produtiva. Essas limitações ficam ainda mais evidentes no que se refere às sistemistas, visto que o desenvolvimento de seus produtos é feito em co-design com a Fiat. Sob esse esquema o

(...) aprendizado é estimulado através da interação entre montadora-fornecedor (learning by interacting) e aprendizagem spillovers (learning by doing and learning by using) são gerados no processo interativo. Como colocado por Loasby (1994), a cooperação entre compradores e fornecedores permite que eles dividam os riscos e ainda apóiem-se mutuamente nas distintas capacitações por eles desenvolvidas na forma de qualificações especializadas, informação e conhecimento tácito de processos e técnicas (LEMOS et alli, 2000, p. 19).

Por causa desse tipo de relação, constata-se que os vínculos mantidos com universidades e centros técnicos não são muito fortes, como colocado por Santos, Crocco \& Lemos

(...) a relação das empresas multinacionais com a rede de conhecimento local estaria limitada às atividades de capacitação gerencial e de engenharia de processo e de treinamento e educação da mão-de-obra ligada diretamente à produção (neste caso, voltada para a adaptação aos requisitos do JIT [just in time] e dos sistemas de qualidade) (2002, p. 166).

Levando em consideração tal estrutura, pode-se perceber que a capacidade inovativa do arranjo de Betim é baixa, pois as atividades de P\&D têm baixa relevância para o desenvolvimento de produtos locais. Por esse motivo,

(...) o fortalecimento de relacionamentos cooperativos inter-firmas é ameaçado, uma vez que a relação é centrada mais em preços, capacidade de entrega e requerimento de qualidade, do que em troca de informações tecnológicas sobre produtos e aprendizagem. Neste caso, os efeitos de encadeamento para trás e as externalidades provenientes de acordos cooperativos são colocados em risco (LEMOS et alli, 2000, p. 28). 
Com relação à Ford, sua estrutura produtiva e organizacional se assemelha muito à da Fiat. Tendo em vista que essa montadora também apresenta governança do tipo hierárquica, a empresa lidera o processo inovativo, enquanto a maioria de seus fornecedores não possui departamentos de $\mathrm{P} \& \mathrm{D}$, sendo assim as sistemistas apresentam “(...) uma maior concentração nas inovações relativas a desenho de produto, implementação de técnicas avançadas de gestão, significativas mudanças na estrutura organizacional, e implementação de novos métodos e gerenciamento visando atender a normas de certificação" (GUERRA \& MERCÊS, 2004, p. 10). Evidencia-se, então, a extrema relevância da coordenação exercida por parte da montadora, pois como as sistemistas não possuem significativos investimentos em P\&D e também segundo, Guerra e Mercês, as mesmas não possuem qualquer vínculo com universidades, centros técnicos e instituições de apoio, elas tornam-se dependentes das ações inovativas da Ford. No entanto, a montadora considera importante

(...) as ações conjuntas realizadas com as sistemistas, principalmente no que diz respeito à melhoria, desenvolvimento e condições de fornecimento dos produtos, melhoria nos processos produtivos, capacitação de recursos humanos, bem como na introdução de inovações organizacionais (GUERRA \& MERCÊS, 2004, p. 12).

Em comparação com o arranjo da montadora Fiat, no arranjo da Ford percebe-se também elevado nível de subcontratação, o qual mantém certa hierarquização. De acordo com Guerra \& Mercês,

(...) cerca de $50 \%$ dos fornecedores subcontratam outras empresas do arranjo, de maneira que existem subcontratações cruzadas de atividades como fornecimento de insumos e componentes, serviços especializados na produção, atividades administrativas, serviços gerais e etapas do processo produtivo (2004, p.12).

Entretanto, constata-se que os requisitos tecnológicos e produtivos desses fornecedores são adequados de acordo com a demanda da Ford, conseqüentemente, essas empresas estão atreladas às decisões da montadora. Tendo isso em evidência, o processo de aprendizagem do arranjo se dá por dois meios: um interno às empresas em interação com seus próprios departamentos de $\mathrm{P} \& \mathrm{D}$ (aquelas que têm) ou em interação com a Ford (learning by doing); outro externo a elas, ao interagirem com seus fornecedores/clientes. No entanto, cabe salientar que o principal meio de aprendizagem é o interno, pois a Ford tende a eliminar as deficiências em termos de falta de experiência por parte desses fornecedores que se implantaram ou não no local para atender às necessidades produtivas da montadora, esta consideração foi levantada pela maioria das sistemistas na pesquisa de campo realizada por Guerra \& Mercês (2004). No que se refere a outras vias de aprendizado, como universidades e instituições de apoio, foi apontado nessa pesquisa que aproximadamente 50\% das sistemistas 
de médio porte possuem vínculos com esse tipo de instituição, apesar das principais interações se darem entre a montadora e aquelas instituições de ensino.

Contudo, vêm sendo dispostos cursos de qualificação técnica e treinamento de recursos humanos por parte de instituições pára-estatais, resultando em uma endogenização do processo de aprendizado, o que se torna de grande relevância devido à anterior falta de mão-de-obra qualificada local para suprir a demanda da respectiva montadora. Neste ponto, os arranjos se diferem, pois em Betim já estava constituída toda uma rede de infra-estrutura educacional para atender à especialização básica, o que não é verificado no arranjo produtivo em Camaçari, sendo essa a principal externalidade negativa apontada no último. Por esse motivo, Guerra \& Mercês destacam que por mais que

(...) pese os esforços do governo de estado e de algumas instituições como o Centro Integrado de Manufatura e Tecnologia (CIMATEC) da Federação das Indústrias do Estado da Bahia (FIEB), o SENAI local e as universidades públicas e privadas, que já criaram cursos nessas áreas, há ainda uma grande deficiência na disponibilidade de profissionais experientes, quer seja para o ensino e pesquisa, quer seja para atuar na produção industrial. (2004, p. 14).

Levando tudo isso em consideração, podem-se perceber as principais diferenças e semelhanças da interação entre os agentes participantes dos arranjos de Betim e Camaçari, suas respectivas formas de governança e de aprendizado entre as sistemistas com suas relativas empresas-âncoras.

\section{Conclusão}

Diante do panorama apresentado, verifica-se que existe certa precariedade nas interações entre os atores locais nos dois arranjos estudados. No caso da Fiat, percebe-se que o processo de "italianização" debilitou o processo inovativo interno ao arranjo, pois ao tornálo como mero pólo produtivo, as empresas tornaram-se dependentes dos departamentos de P\&D de suas matrizes, o que delimitou os laços com instituições de apoio, como universidades. Em decorrência deste fator, o arranjo de Betim encontra-se bastante hierarquizado, o que de certa forma, atrofia as relações entre as sistemistas e as sistemistas/montadora, não permitindo a pleno estabelecimento de vínculos de confiança e de cooperação, o que também decorre da forma como a montadora mantêm suas relações com seus fornecedores globais.

Com relação à Ford, as fragilidades tornam-se mais evidentes, devido ao curto período em que o arranjo encontra-se estabelecido. Como no caso da Fiat, percebe-se um elevado nível de subcontratação, gerando um nível de hierarquização bastante elevado. No entanto, o 
fator mais relevante desse arranjo é a debilidade com relação à qualificação profissional local, o que torna as relações entre as sistemistas e instituições de apoio mais próximas. Contudo, mesmo com essa maior proximidade, ainda não houve maiores avanços com relação ao desenvolvimento da capacidade inovativa do arranjo e também à fortificação dos vínculos de confiança e de cooperação entre os atores locais.

Neste sentido, verifica-se que os arranjos apresentados apresentam desenvolvimento estrutural debilitado. Isto é perceptível não somente por essas aglomerações estarem inseridas num país em desenvolvimento, mas também por parte das estratégias das grandes montadoras, as quais mantêm esses arranjos como plataformas de montagem, sem serem exigidas grandes alterações no produto, apenas a "tropicalização" dos carros.

Deste modo, todos esses aspectos em conjunto, apresentam-se como barreiras a serem transpostas para o alcance do desenvolvimento local, a fim de que posteriormente sejam alcançadas as condições necessárias para a criação de vínculos sociais, ou seja, níveis altos de confiança entre os atores locais, identidade cultural entre eles e a competição inter-firmas baseadas na inovação. Tudo isso com o objetivo de propiciar um ambiente capaz de elevar o grau de interdependência entre as empresas, conduzindo a um processo de aprendizado social e interativo, com o pleno desenvolvimento das capacidades inovativas das aglomerações.

\section{Referências Bibliográficas}

BOTELHO, Marisa dos Reis A. Los distritos industriales em países emergentes. El caso del Brasil. Revista Mediterráneo Económico (Espanha), v.13, 2008, p. 225-48.

CASSIOLATO, José Eduardo; SZAPIRO, Marina. "Uma caracterização de arranjos produtivos locais de micro e pequenas empresas". In: LASTRES, Helena Maria Martins; CASSIOLATO, José Eduardo; MACIEL, Maria Lucia (orgs). In: Pequena Empresa: cooperação e desenvolvimento local. Rio de Janeiro: Relume Dumará: UFRJ, Instituto de Economia, 2003.

; LASTRES, Helena Maria Martins.”O foco em arranjos produtivos e inovativos locais de micro e pequenas empresas". In: LASTRES, Helena Maria Martins; CASSIOLATO, José Eduardo; MACIEL, Maria Lucia (orgs). In: Pequena Empresa: cooperação e desenvolvimento local. Rio de Janeiro: Relume Dumará: UFRJ, Instituto de Economia, 2003.

CROCCO, Marco Aurélio et alli. Metodologia de identificação de aglomerações produtivas locais. Revista Nova Economia, v.16, n.2. Belo Horizonte: maio/agosto, 2006. p. 211-241.

DINIZ, Clélio Cammpolina. O papel das inovações e das instituições no desenvolvimento local. Disponível em <http://www.anpec.org.br/encontro2001/artigos/200105383.pdf>, 2001, acessado em 20/07/2008. 
FERREIRA, Fátima; LEMOS, Mauro Borges. A nova configuração geográfica da indústria automotiva no Brasil. Revista de Desenvolvimento Econômico, ano VI, n.10. Salvador: julho, 2004. p. 47-59.

GUERRA, Oswaldo; MERCÊS, Raimundo. MPEs no Arranjo Produtivo da Ford Nordeste/BA. Programa de pesquisa sobre Micro e Pequenas Empresas em Arranjos Produtivos no Brasil. Florianópolis: UFSC, 2004.

LEMOS, Mauro Borges; DINIZ, Clélio Cammpolina. Sistemas regionais de inovação: o caso de Minas Gerais. (Globalização e inovação localizada: experiências de sistemas produtivos locais no âmbito do Mercosul e proposições de políticas de C\&T. Nota técnica 06/98). Rio de Janeiro: Instituto de Economia da Universidade Federal do Rio de Janeiro(UFRJ), 1998.

; DINIZ et alli. Arranjos produtivos da Rede Fiat de fornecedores.

Arranjos produtivos locais e as novas políticas de desenvolvimento industrial e tecnológico. BNDES/ FINEP/ FUBJ. Relatório Final. Belo Horizonte: 2000.

LIMA, Carmen Lucia et alli. Fornecedores da Ford: uma avaliação preliminar das oportunidades de investimento na Bahia. Estudo Setorial. Salvador: Agência de Fomento do Estado da Bahia-Desenbahia, set., 2002. Disponível em $<$ http://www.desenbahia.ba.gov.br/recursos/news/video/\%7BC7766185-8414-4092-B671804BD991141E\%7D_fornecedores_da_ford.pdf>, acessado em 25/07/2008.

NARETTO, Nilton; BOTELHO, Marisa dos Reis; MENDONÇA, Mauricio. A trajetória das políticas públicas para pequenas e medias empresas no Brasil: do apoio individual ao apoio a empresas articuladas em arranjos produtivos locais. Revista Planejamento e Políticas Públicas, n.27. Jun/dez, 2007. p. 61-115.

RESENDE, Marco Flávio da Cunha; GOMES, Jefferson de Oliveira. Competitividade e potencial de crescimento do cluster de produtores de moldes para a indústria de plásticos de Joinville. Revista Nova Economia, v.14, n.1. Belo Horizonte: jan./abril, 2004. p. 67-104.

SANTOS, Ângela Maria Medeiros M.; GUARNIERI, Lucimar da Silva. Características gerais de apoio a arranjos produtivos locais. Rio de Janeiro: BNDES Setorial, n.12, set., 2000. p. 195-204.

SANTOS, Fabiana; CROCCO, Marco; LEMOS, Mauro B..Arranjos e sistemas produtivos locais em "espaços industriais" periféricos: estudo comparativo de dois casos brasileiros. Revista Economia Contemporânea, v. 6, n.2. Rio de Janeiro: jul./dez., 2002. p. 147-180.

SILVA, João Carlos Domingos et alli. Estimativas dos efeitos da implantação do complexo Ford nordeste sobre a estrutura industrial da Bahia: uma abordagem insumo-produto. Disponível em <http://www.anpec.org.br/encontro2004/artigos/A04A128.pdf>, 2004, acessado em 25/07/2008. 
VARGAS, Marco Antônio. Aspectos conceituais e metodológicos na analise de arranjos e sistemas produtivos e inovativos locais. Programa de pesquisa sobre Micro e Pequenas empresas em Arranjos Produtivos no Brasil. Florianópolis: UFSC, 2002. 